Behavioural Sciences | David Yeung and Leon Petrosyan

\section{Asynchronous horizons durable-strategies dynamic games}

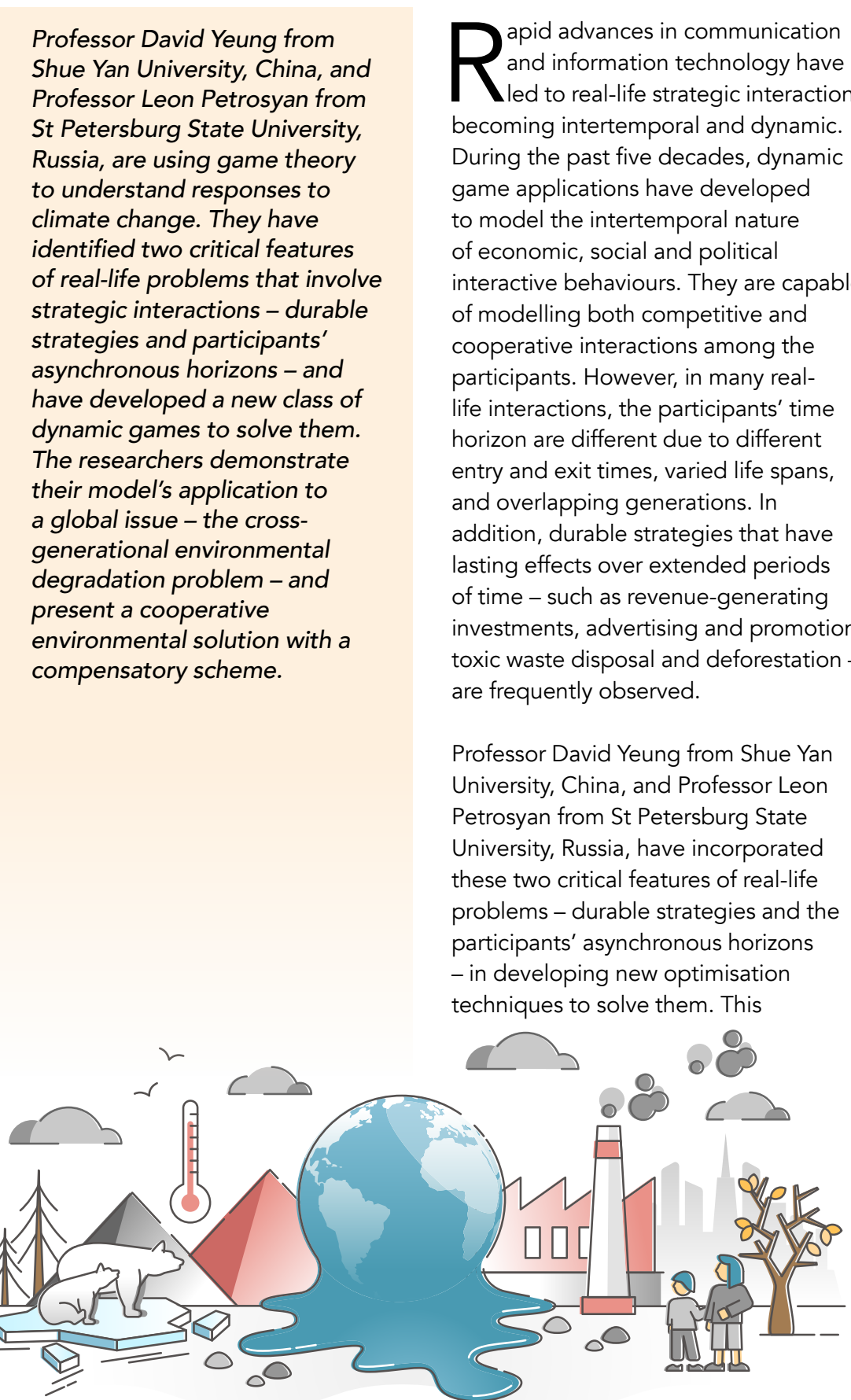

has resulted in the creation of a general class of dynamic games with participants' horizons.

\section{THE ENVIRONMENTAL}

\section{DERADATION PROBLEM}

eung and Petrosyan describe a global Ind durable strategies - the crossgenerational environmental degradation problem. The intergenerational self-seeking maximisation behaviour that underpins the exploitation of environmental commons and the development of alternative green technologies gives rise to significant dynamic externalities, where the actions of the current decision-makers affect the welfare of future generations. This can be through changes in state variables such as the concentration of greenhouse gases in the atmospher the availabilty of clean water and the welfare of future generations.

\section{ENVIRONMENTAL COMMONS}

is more complex than that of a tradable property. Natural ecosystems are made up of physical and biological factors. They comprise abiotic resources such as air, water, soil, rocks, and energy, and interacting life forms such as plants, animals, and micro-organisms that amass into populations that form ecological communities. Ecosystems are long lasting and span generations. Their positive natural elements can provide enormous benefits to huma Eco-degradation resulting from emissions of pollutants and toxins can
Such anthropogenic activities that degrade the environment may cause dure discuss how eco-degrading activities can have durable negative impacts over period of time, and this complicates the dynamic externalities of the

environmental commons.

\section{A NEW CLASS OF}

ENVIRONMENTAL GAMES

Yeung and Petrosyan have developed anew class of dynamic games to analyse the many strategic interactions that occur in the cross-generational environmental degradation problem They demonstrate an asynchrono horizons durable strategies environmental dynamic game, the refects of which are supported by Researchers have demonstrated that
even if carbon dioxide emissions suddenly ceased, the carbon dioxide already present in the Earth's atmosphere could continue to warm the planet for centuries to come. Environmental degradation could therefore continue to worsen, even if a eco-degrading production stopped.

Climate scientists have found that $\mathrm{CO}_{2}$ stays in the atmosphere for thousands of years, so the welfare of late entrants to the game, namely future generations, is affected by the durable negative inpacts of the do-degading outputs

\section{NON-COOPERATIVE EQUILIBRIUM} In game theory, a non-cooperative individual players who compete independently. Equilibrium is a concept that determines the optimal solution in non-cooperative game where players lack any incentive to change from their initial strategy. Durable strategies that have been executed by players who have left the game will continue to affect the state dynamics as well as the payoffs, or welfare, of those players entering the game after their exit. Consequently, in a non-cooperative will contin, envirnmental degrada will continue to worsen over time refer to as a dynamic tragedy of the

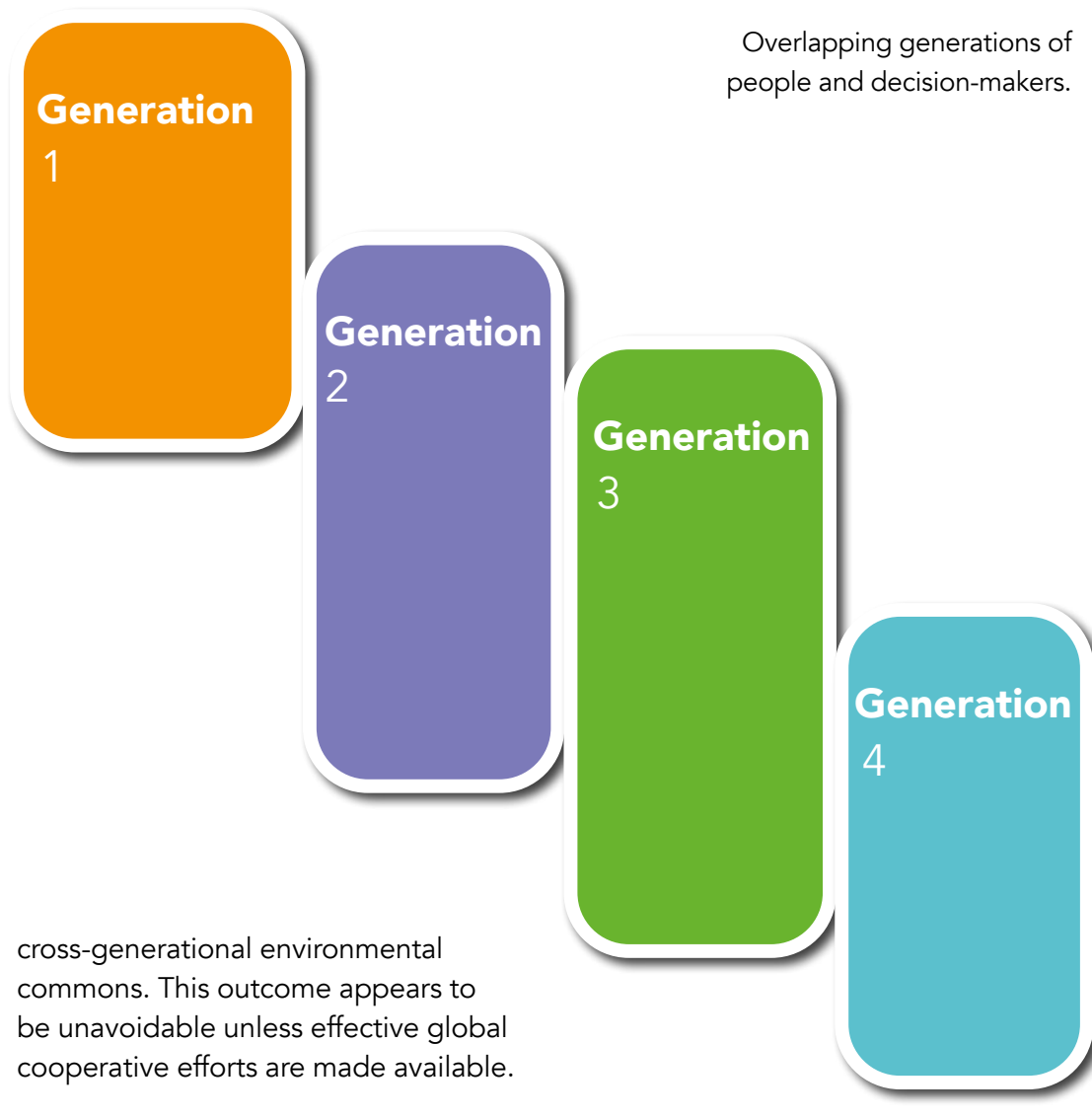

COOPERATIVE SOLUTION

A cooperative game has groups of primary decision-making units. It can be viewed as a competition betwe coalitions of players, rather than individuals. A fundamental assumpt

interactions tend to be handled by sel-interest maximisation. Yeung and Petrosyan explain that efficiency, in payoffs under cooperation, is typicall lost from self-seeking activities,

The exploitation of environmental commons

and the development of alternative green technologies gives rise to significant dynamic externalities across generations. in cooperative game theory is that a particularly when asynchronous
group will form made up of all of the participants' horizons and durable players, known as a grand coalition. The strategies are involved. Price of Anarchy challenge then is to find a fair way to is a measure of the efficiency that is lost allocate the payoff among the players.

A cooperative solution enables the players to exploit the potential gains from cooperation. The players agree to act cooperatively and to distribute the payoffs according to an agreed-upon gain-sharing optimality principle.

\section{PRICE OF ANARCHY}

decision problems that entail strategic due to the participants' self-seeking optimisation. It reveals the shortcomings in an outcome in a competitive situation when the participants act selfishly in the socia opests compared with the Pareto To of the players' payoffs, the researchers maximise the participant' joint payoff efficis the entre game horizon since 


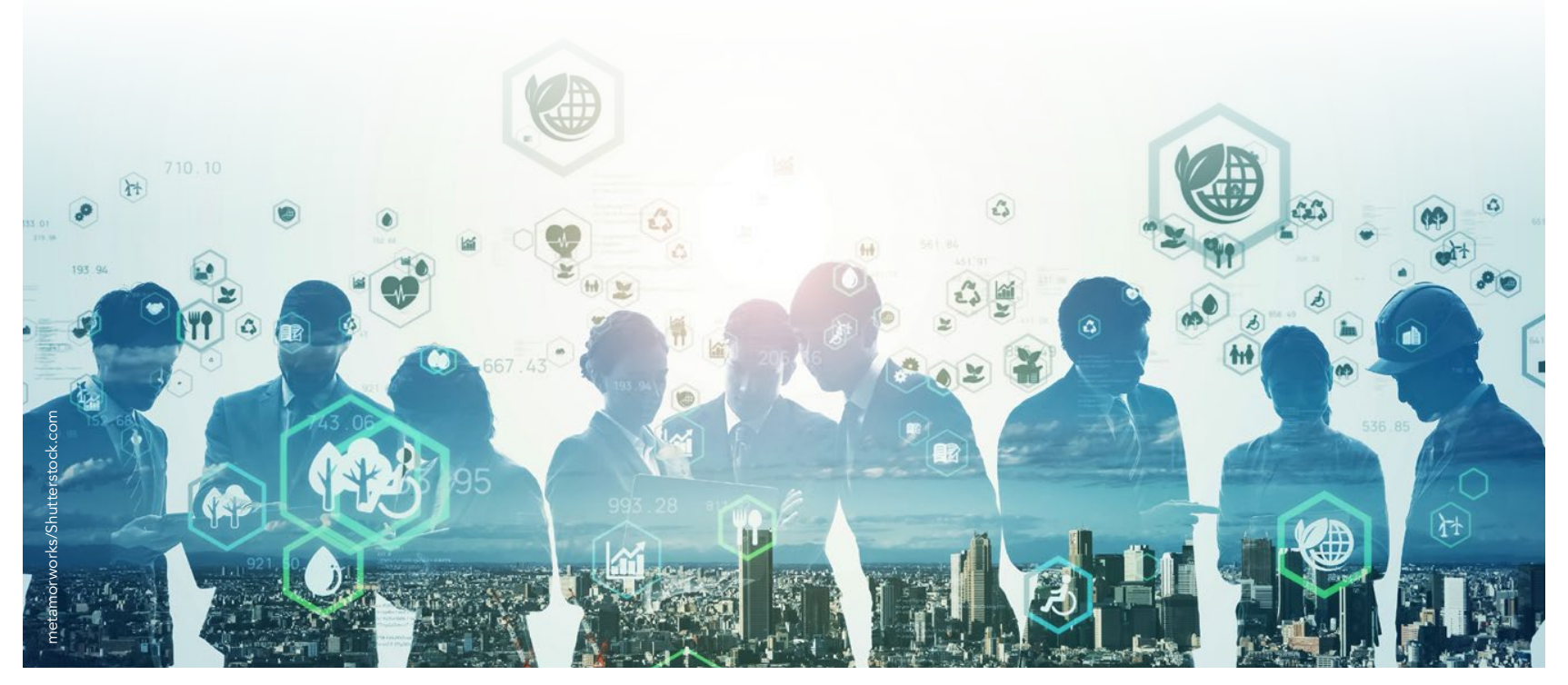

policy requires cooperation across multiple generations of decision making. The Price of the Pareto optimeted by the players' payoffs over the sum of the players' payoffs under

\section{THE CURRENT UNBRIDLED}

\section{PROBLEMS}

Due to the large number of potential players over generations and durable dynamic externalities in using the

Without effective global cooperative efforts, a dynamic tragedy of the crossappears to be unavoidable.

\section{A THEORETICAL COMPENSATORY}

SCHEME

The researchers have developed a theoretical compensatory solution that alleviates the problem of individual players over-exploiting the cross-

generational environmental commons due to their self-interests. This schem

\section{global cooperative organisation that is} (astablished on the bases of comm pursuing by policymakers.

\section{INNOVATION}

Yeung and Petrosyan are breaking ew ground with the development of dynamic games. They provide thorough mathematical solutions supporting this pioneering class of dynamic games with asynchronous players' horizons and

becomes

very severe.

In particular,

self-seeking

optimisation by

Without effective global cooperative

They propose efforts, a dynamic tragedy of the cross-

a cooperative
environmental

solution with a

compensatory generational environmental commons appears to be unavoidable.

will cause serious researchers have damages to the identified two critical co-degradation which effects will be borne by future generations.

At the same time, environmental improvement efforts will be greater under cooperation than under nonreen technology investment, the leve of green technology under cooperation will also be higher than under noncooperation. Thus, the clean outputs produced under cooperation is deemed to be higher than those produced under non-cooperation. The sluggishness in advancing the development of green technology to its full extent is very much players across generations. provides an acceptable distribution of the cooperative gains that is satisfactory for all participants throughout the entire cooperative duration.

Achieving efficient environmental resource allocations with global dynamic externalities requires the cooperation of many nations over a long time-horizon and involves several generations of stakeholders. This requires complex intertemporal strategic interactions decision-makers. Yeung and Petrosyan offer a solution that generates an efficient outcome analogous to that produced in a game where long-lived players under cooperation provide gains for all participants. Accomplishing this eatures in real-life problems - durable strategies and asynchronous horizons two features play a critical role in the exploitation of cross-generationat environmental commons.

\section{BROADER IMPAC}

In addition to academic researchers, government and industry, this research will be of particular interest to policymakers involved in internationa climate control, as well as those members of the general public with degradation. It is also expected to shed some light on current global climate polices, such as the Paris Agreement Climate Change. concerns regarding environmental

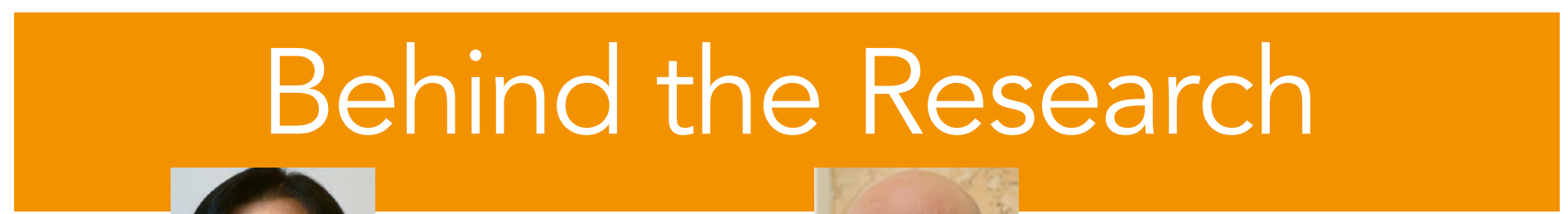

Professor David Yeung

Professor Leon

Petrosyan

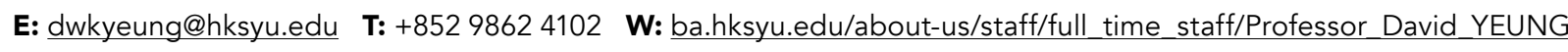

Research Objectives

Using dynamic game theory to present solutions to the cross-generational problem of environmental degradation.

\section{Detail}

\section{Address}

SRS Consortium for Advanced Study in Cooperative Dynamic Games, Shue Point, Hong Kong.

avid Yeung is Distinguished

\section{References}

Yeung, DWK, and Petrosyan, LA, (2021). Asynchronous Horizons Durable-Strategies Dynamic Games and Tragedy of Cross-Generational Environmental Commons

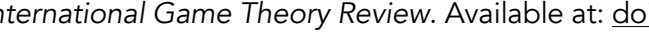
org/10.1142/S021919892150020

Yeung, DWK, and Petrosyan, LA, (2021). Generalized ynamic games with durable strategies under uncertain planning horizon, Journal of Computational and Applied cam.2021.113595.

Petrosyan, LA, and Yeung, DWK, (2020). Cooperative Dynamic Games with Durable Controls: Theory and Application, Dynamic Games and Applications, 10, 872896. Available at: doi.org/10.1007/s13235-019-00336-w.

Yeung, DWK, and Petrosyan, LA, (2019). Cooperative Dynamic Games with Control Lags, Dynamic Games and Applications, 9(2), 550-567. Available at: doli.org/10.1007/ s13235-018-0266-6.

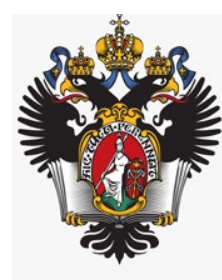

Leon Petrosyan is Dean of Faculty of Applied Mathematics \& Control School of Management at St Petersburg State University. He obtained his PhD from Vilnius University and Dr.Sc from St Petersburg State University. His main theory and optimal control.

\section{Personal Response}

What inspired you to apply the asynchronous horizons durable strategies environmental dynamic

II One of the most noted global issues affecting mankind is the accelerating environmental degradation. is a clissic the exploitation of the environmental commons is a classic case of participants with asynchronous
decision horizons and industrial strategies causing Iong-term harmful effects. Serious negative externalities indeed exist in intergenerational self-maximisation behaviour in exploiting the environment under common access. What makes the cross-generational externalities have durable negative impacts beyond the participant decision horizon. The non-cooperative game equilibria and proposed cooperative solution would shed light on
the decisions made in the policy forum. the decisions made in the policy forum.

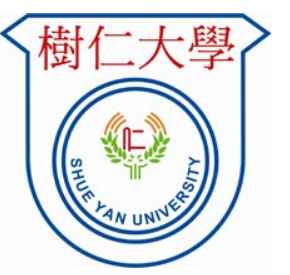

